\title{
Chalkface; interface; screenface: moving the metaphor of teaching towards the nexus of teaching and learning
}

\author{
Alison Ruth* \\ Faculty of Business, Economics and Law, La Trobe University, Melbourne, Australia
}

(Received 12 May 2011; final version received 8 January 2012)

This paper provides a nuanced metaphor for teaching and learning, taking into account newer mediated forms of learning that lie at the nexus of teaching and learning. Firstly, the paper navigates this metaphorical minefield by tracing the evolution of the terms for describing learning environments: specifically coalface, chalkface and interface. Secondly, it addresses ways of thinking about curriculum design, taking account of the different actors involved in curriculum - designers, teachers and learners - at the chalkface, the interface and in the proposed new metaphor - the screenface. The screenface metaphor is then elaborated both in terms of the shifts in thinking it can facilitate and the implications of viewing research into teaching and learning through this lens. The screenface is a useful metaphor, with application beyond this initial proposal providing new and fruitful questions that can be asked about teaching and learning.

Keywords: teaching; learning; technology; curriculum

\section{Introduction}

The common metaphor for teaching in schools is 'the chalkface', where teaching is privileged over learning, as it focuses on the activities of the teacher. More studentcentred approaches have reduced the value of this metaphor, yet it still pervades thinking about teaching. For example, we distinguish lecturers from policy makers and staff developers with this metaphor. In this paper, I present a new metaphor, the 'screenface', which simultaneously privileges both teaching and learning. To do this, I start with a brief history of the chalkface, its use, and similarities to the 'coalface'. I then elaborate the application of Burke's pentad to the 'coalface' using Freeman's (1974) models. Next, the interface is analysed through the pentadic lens, before moving to a description of how this manifests in the screenface. I conclude with a discussion of the ways this metaphor allows us to question our approach to learning through research. The future of the metaphor is likely to be open to contestation (see for instance Rowland 2006) because of the interdisciplinary nature of our approaches to teaching and learning and the challenges associated with the adoption of metaphors between disciplines.

The metaphor of the 'screenface' owes something to the terms 'chalkface' of faceto-face instruction and, preceding that, the 'coalface', the point at which coal is removed from the seam, the location of work. These terms are used as metaphors for

\footnotetext{
*Email: a.ruth@1atrobe.edu.au 


\section{A. Ruth}

those who work 'on the ground', as opposed to those who sit at a distance and make decisions. Coal mining has always been an extremely dirty, dangerous and 'immediate' activity, particularly prior to the advent of machinery to facilitate coal extraction (immediacy, here, refers to the need to be almost hyper-aware of the environment). Similarly a chalkface, like the 'White Cliffs of Dover', is an expanse of chalk that may be mined, but again, a dangerous undertaking. The movement of this latter term to the teaching profession is almost a result of how many teachers viewed their work - dangerous, dirty and altogether un(der)appreciated.

So why did the term resonate so with teachers? The chalkface was where the activity of teaching occurred, the bulk of the work being carried out by the teacher in providing guidance for learners. The term became a metaphor to distinguish the work done by those 'on-the-ground' as opposed to managers and policy makers working 'at a distance'. The juxtaposition of the two words 'chalk' and 'face' (and the actual use of chalk) together with its similarity to the coalface provided a seemingly useful metaphor for teaching, although it appears that it has rarely been interrogated as a metaphor.

Arnold (1996, p. 230) comes closest to defining the chalkface in his discussion about the influence of unions in Australian teaching stating that schools have been rhetorically constructed as "the chalk face" - a pedagogical work place'. Many other authors use the term in similarly rhetorical ways to differentiate the act of teaching from the act(s) of researching/policy making about teaching, but it is still wholly uninterrogated. If the chalkface is a pedagogical work place, then the focus of the activities is on the teacher's interaction with the chalkface and, indeed, it is the teacher in control of the process and the 'on-the-ground' expert.

Given the rhetoric on 'student-centred learning', a movement away from the use of the chalkface as the dominant metaphor for the teaching/learning nexus seemed inevitable. There is a shift towards the use of the term 'interface' to describe the development of computer-mediated teaching/learning. For instance, Bramall (2000, p. 76) discusses how the "whole system of representation of interfaces is metaphorical, as is much of the enabling language of cyberspace', concluding with the observation that the 'interface may have the potential to be as productive as the chalk-face' (Bramall 2000, p. 83). However, the interface itself differs from the chalkface because both teacher and student interact directly with an interface, rather than simply viewing the chalkface as students have traditionally done (perhaps a precursor to the 'interface' is where students are required to complete some work on the board, although, for the student, this may be more performative than interactive). To date, there has been no compelling metaphor to assist in explaining cognitive work in mediated environments.

In this paper, I propose a new metaphor, the screenface, for learning in digital environments, a metaphor that develops from the chalkface, but allows an interrogation of it and of any metaphor we claim assists in clarifying interactions between teachers and learners. Like many metaphors, the fit is often not complete; however, the power in this metaphor is that it demonstrates applicability from the chalkface through the interface and to the screenface, a teleological proposition for interacting with a computer (and thus the people beyond the screenface). I start with an analysis of classroom situations, visit the newer metaphor of the 'interface' aka the "glass screen" (Arnold 2001) - and arrive at our destination of the screenface. 


\section{The chalkface: analysing classrooms}

A useful starting point for discussing classroom interactions is provided by Freeman (1974). A focus on curriculum provides a coherent framework for elaborating how interactions are constituted. Freeman (1974) used Burke's (1945) Grammar of Motives to analyse classroom curriculum, noting that the classroom "environment must be a carefully organized and sequenced arrangement of materials, facilities and activities that provide the necessary background for transmitting the appropriate knowledge" (Freeman 1974, p. 5) where the focus is on an "intellectual discipline orientation", which is equivalent to "transmission of knowledge". The other models of curriculum that Freeman discusses are the self-actualizing orientation and the behavioural model. The self-actualizing model places a "premium on the unique individual", that is, it is student centred, and the behaviouristic model is a "planned environment' in which all contingency situations are programmed".

The first model, the knowledge transmission model, "serves to impart the content and skills of the organized fields of knowledge which have their own histories, principles, and methodologies" (Freeman 1974, p. 6). This model is embedded in tertiary education with current teachers demonstrating concern about covering content and including all relevant 'facts'. The second model, the self-actualizing model states "education should develop and fulfill [sic] the individual student's talents, needs, interests and abilities" (Freeman 1974, p. 6). This model closely resembles forms of learning, including problem-based models. The final model, the behaviouristic model, aims to "condition the individual by scientifically controlling and shaping his environment". Again, this model is apparent in many teaching scenarios (e.g. laboratory sessions). Each of Freeman's models provides some connecting feature with classrooms both face-to-face and via computer mediated technologies.

Burke's (1945) pentad from Grammar of Motives provides multiple angles to arrive at such an analogy. The five elements of the pentad are: act (that which is done), agent (who does it), agency (the manner through which it is done), scene (where it is done) and purpose (why it is done). Note that in Burke's pentad, agency is the processes/tools and/or implements used by agents to perform acts in a scene for a purpose. The pentad demonstrates how multiple perspectives allow explication of interactions within a particular scenario. Freeman's analysis of curriculum through Burke's pentadic lenses allows a description of curriculum that forms the basis of this paper's analysis of classroom interaction.

In Burkean terms curriculum can be conceived as a set of five basic motivational forces: a curriculum guide (Burke's act), authored by curriculum designers (Burke's agent) to serve as a motivational ground (Burke's scene) for subsequent actions, thereby an instrument (Burke's agency) for shaping human relations (Burke's purpose) (Freeman 1974, pp. 3-4)

As will be demonstrated, in Burkean terms, each of the 'faces' of teaching and learning provide nuanced understandings of the processes at play.

Freeman's analysis focuses specifically on curriculum design; however a focus on the classroom brings to the fore another two sets of interactions that happen in the classroom - the location of the chalkface. As noted above, the chalkface serves to distinguish the curriculum design (which often happens at a policy and/or accreditation level) from the actual structure of interactions in the classroom. Table 1 shows the concurrent sets of 'motives' (with three embedded curricula models from Freeman 1974) operating in the classroom. 


\section{A. Ruth}

Table 1. Burke's elements mapped onto classroom situations for the two main agents within classrooms incorporating the chalkface (teacher perspective) and the classroom (student perspective).

\begin{tabular}{|c|c|c|c|}
\hline $\begin{array}{l}\text { Burke's } \\
\text { element }\end{array}$ & $\begin{array}{c}\text { Freeman's curriculum } \\
\text { design }\end{array}$ & \multicolumn{2}{|c|}{ Chalkface (Classroom) } \\
\hline Agent & Designers & Teacher & Student \\
\hline Scene & Motivational ground & Classroom (with desks) & $\begin{array}{l}\text { Desks (in a } \\
\text { classroom) }\end{array}$ \\
\hline Agency & $\begin{array}{l}\text { Instrument (for the } \\
\text { purpose) }\end{array}$ & Talk and chalk & Pen and paper \\
\hline Act & Curriculum Guide & $\begin{array}{l}\text { Persuasive (behaviouristic) } \\
\text { Expressive (child-centred) } \\
\text { Scientific (transmission) }\end{array}$ & $\begin{array}{l}\text { Listening quietly } \\
\text { Actively responding } \\
\text { Passively receiving }\end{array}$ \\
\hline Purpose & $\begin{array}{l}\text { Shaping human } \\
\text { relations }\end{array}$ & $\begin{array}{l}\text { Control (behaviouristic) } \\
\text { Engaging (child-centred) } \\
\text { Structure(transmission) }\end{array}$ & Learn \\
\hline
\end{tabular}

From this table, it becomes clear that, depending on the point of the analysis, the agent requires different views of what happens in the classroom. Each participant is joined in a concurrent set of activities, yet they are often polar opposites. The purpose of the interactions, at a fundamental layer, is for the student to learn and yet the purposes embodied in curriculum (for 'shaping human relations') range from control of student behaviour through structuring those processes and then to engaging the learner. The scene and agency also clearly demonstrate this opposition, with a different aspect of the classroom being foregrounded, the classroom (with a chalkboard) versus the desk (in the classroom) and the equipment used to engage with knowledge constructing activities. Depending on the curricula model, the act also changes with two complete sets of oppositional acts. Hence, Burke's model can provide multiple perspectives of the same set of activities.

Delving further into Burke's model, the interaction between elements provides deeper understanding of the interplay between elements. For instance, in the above scenarios, the Agent:Act dyad shows that the teacher as agent 'teaches' that which the learner as agent 'learns'. These are conjoined activities but with opposing viewpoints (represented by the 'scene'). Similarly, the Agent:Agency:Act triad demonstrates that a teacher talks to learners while writing on the board (among other activities) while the learners listen and watch, then write the information/ideas down.

However, the metaphor of the chalkface essentially excluded learners, because the 'pedagogical place of work' is at the board. Students rarely ventured to interact with it and indeed were precluded from it except for instances of punishment (refer to Bart Simpson in the opening of 'The Simpsons') or as a reward for good work. Similarly, in a tertiary environment, students are lectured to and there are many discussions about developing interactive lecture approaches (see for instance Rodger 1995; Van Dijk, Van Der Berg, and Van Keulen 2001; Wessels et al. 2007). Thus when using the pentad to refer to the chalkface, agency is restricted to acts by the teacher (agent) and excludes the learner (agent). This is a fundamental flaw in the metaphor, which precludes it from current debates that focus on 'student-centred' learning.

At this point, I move towards a newer metaphor - the interface, which arises from computer mediated interactions. 


\section{The interface}

Freeman's description of curriculum serves to provide a directly comparable analogy to the interface as a 'transmission' of knowledge or information process. In the interface, there is less focus on 'control of behaviour' and engagement is a contested term within computer-mediated communication. An early measure of interactivity (engagement) is what Singh (2003) calls "page-turner content", that is, measurement of clicks on hotspots.

Hillman, Willis, and Gunawardena (1994, p. 32) introduced the 'interface - the point or means of interaction - between the learner and his or her content, instructor, and fellow learners' as a fourth dimension of interaction for distance learners. Sharples (2002, p. 9) discussed how, in a mobile environment, "the system can present the learner with an interface and mode of interaction that is consistent, intuitive and enabling". However, what Hillman, Willis, and Gunawardena and also Sharples did not account for were the two layers of interaction encountered in learning environments - designer-teacher, and teacher-learner. A third layer, student-designer, is implied but is a more distal form of interaction (mediated interaction). The interface then, is a designed environment to achieve the requirements of the learning task. It is focused by the designer (not necessarily the teacher) to draw the learner in. The teacher becomes a guide, directing student activities towards the desired outcomes. Of course, the designer role may be one portion of a teacher's role, but often different processes are required to achieve the ends. The designer role is almost equivalent to Freeman's curriculum designer and is one step removed from the learning interactions. Table 2 outlines the roles of the individual using the interface.

The consideration of multiple roles in Table 2 assists in defining the roles of all individuals within a learning environment. Each agent may have a different interface to the software, depending on their role. This is particularly evident in that the student rarely, if ever, interacts with the teaching mode interface and never with the designer mode. Similarly, for a teacher, their main interaction is via a teaching mode interface, which allows monitoring of different aspects of interaction including surveillance of all student activities. Surveillance provides a semblance of Freeman's "behavioural" model of curriculum design, while also noting whether the student has engaged with the content in a transmission model, that is, if a student does not click every link in order, the complete transmission of information may be broken.

Similarly, the agency used in the interaction is dependent upon which interface is being presented. The designer may be using specialist software (for example photo manipulation software), the teacher may be using an interface version that allows the

Table 2. Burke's elements mapped against the interface for actors in a learning environment.

\begin{tabular}{|c|c|c|c|}
\hline Burke's element & & Interface & \\
\hline Agent & Teacher & Student & Designer \\
\hline Scene & $\begin{array}{l}\text { Software interface } \\
\text { (teaching mode) }\end{array}$ & $\begin{array}{l}\text { Software interface } \\
\text { (learning mode) }\end{array}$ & $\begin{array}{l}\text { Software interface } \\
\text { (design mode) }\end{array}$ \\
\hline Agency & Design/viewing software & Viewing software & Design software \\
\hline Act & $\begin{array}{l}\text { Selecting and } \\
\text { presenting activities }\end{array}$ & $\begin{array}{l}\text { Activities (reading, } \\
\text { clicking etc) }\end{array}$ & Constructing activities \\
\hline Purpose & Engage learners & $\begin{array}{l}\text { Learn (access to } \\
\text { knowledge) }\end{array}$ & $\begin{array}{l}\text { Designing for } \\
\text { learning }\end{array}$ \\
\hline
\end{tabular}


switching of images dependent on the context, while the student will only see what has been prepared for them.

The act enabled for each agent is also different. The designer focuses on constructing those activities, the teacher selecting and presenting those activities, while the student is the recipient of those designs and selections. The purpose echoes these different focuses. Each agent comes to the interface for a different purpose.

The interactions between the different elements also elaborate how the different models of learning play out. For instance, in an ideal environment, a designer interacts with a teacher to develop the learning activities that the teacher desires for the learner. In reality, the designer has little interaction with the teacher, instead, designing a predefined set of activities from which the teacher then selects to enable the learner to learn. This is a conjoined Act:Agent dyad. Teachers may also act as designers, but neither the specialist software, nor the time (or skills) to develop the resources may be available to them.

Similarly, the Agent:Agency:Act triad demonstrates how the activities are interconnected and yet separate. The designer interacts with the teacher in developing the learning activities with design software, although the teacher may be represented by a curriculum specification designed previously. The teacher assesses potentially many designs prior to selecting an appropriate version for their students. The learners then interact with the design under the guidance of the teacher. The very definition of who the agent is shapes what they can do (the act) and the manner in which they can do it (their agency). This definitional constraint suggests the need for a more comprehensive picture of interaction. I propose the 'screenface' as an interaction environment that provides this comprehensive picture of interaction.

\section{The screenface}

The screenface is an interaction environment. Design still precedes it, however the focus of activities is on the current manifestation of applications. Each application has an interface but users are able to switch between layers. Information can be gathered in a browser, copied to a word processor, modified, and then copied back to the browser or even presentation or email software for the purpose of communicating. There is a more encompassing view of the activities being undertaken. Table 3 shows how the screenface makes the scene and agency more coherent for all agents while taking into account the multiple layers therein.

Table 3 demonstrates the coherence in using a deeper metaphor for the 'learning space'. Consideration of the potentials of the wider view of the computer interface, for instance, so-called multitasking (although more often a form of serial monotasking) sees the scene coalesce into a single framework. Likewise the agency an agent uses becomes the many forms of software available to participants in the interaction. Each participant has a unique setup, yet there is sufficient consistency in the kinds of software being used. The unique setup is also manifest in the personalisation that many people apply to their desktop. The acts for each agent also move closer together, although there are still unique features for each agent. But, the purpose of their agents acts become focussed on interactions and communicating those interactions centred on sharing of knowledge. This is a strength of the metaphor which moves beyond simple transmission modes enabled by the chalkface.

Likewise, the interactions between elements of the pentad shows convergence in the Act:Agent dyad because the teacher and the student are both now 'interacting'. 
Table 3. Burke's elements mapped against the screenface for actors in a learning environment.

\begin{tabular}{llll}
\hline Burke's Element & \multicolumn{2}{c}{ Screenface } \\
\hline Agent & Teacher (Learner) & \multicolumn{1}{c}{ Student (Teacher) } & Designer \\
Scene & & Computer screen, layers of interfaces \\
Agency & Browser, email client, other software \\
Act & Interacting/guiding & Interacting/following & Constructing activities \\
Purpose & Interacting to & Interacting to & Designing for people to \\
& give and receive & receive and give & interact to give and \\
& knowledge & knowledge & receive knowledge \\
\hline
\end{tabular}

This interaction is via a browser albeit a more vicarious form of interaction, implying that the agency an individual uses (the browser, email etc.) is shifting it towards the Agent:Agency:Act triad. There are multiple layers of mediation (forms of agency available to the actor) within the learner:teacher interactions providing a deeper appreciation of the processes involved.

This brief analysis of the metaphor demonstrates a more complete account of the processes involved in learning environments. The screenface implies not only the screen, the location (scene) of interaction, but also the layers beyond. The screen has a physicality to it and it can be touched, but the layers beyond are virtual and need the mediation (agency) of mouse, keyboard or touch interface to effect. This is the first layer of interactional mediation. Other layers include the application interfaces, the Internet connection and all that it includes (also an application interface, the application being the Internet). Underlying these, the base level for the interaction is the desktop.

Thus the screenface, while a single metaphor, represents an infinite number of potential descriptions as each person personalises their computer. Each computer thus works differently and it is this layer of individualisation over the original mediation that adds complexity unaccounted for in other metaphors.

\section{Features of the metaphor}

\section{Terministic screens}

Given the application of the screenface metaphor to computer-mediated environments, can it be applied to the interface and chalkface? Burke's concept of "terministic screen" applies here. For Burke, a terministic screen filters our representation of what is by allowing (and depending upon) particular focus of specific terminology:

Even if any given terminology is a reflection of reality, by its very nature as a terminology it must be a selection of reality; and to this extent it must function also as a deflection of reality (Burke 1966, p. 45, italics in original).

So each metaphor used, by its very nature, provides a screen through which we view and discuss what we see. Therefore the chalkface (and the coalface) implies certain views of reality. For instance, the chalkface is "where the pedagogical work is done" (Arnold 1996) thereby excluding learners because they do not interact with the chalkboard and implies they are not really pedagogical agents. This deflects a view of pedagogy as something that is enacted by co-agents, that is learners and teachers, towards a view where pedagogy is enacted upon learners by teachers. Similarly, the 
interface deflects from both agents - teacher and learner, focusing our thoughts on the computer itself. However, the screenface implies, and is constructed around, an individualised manifestation of the environment thereby positing the agent as part of the scene. The screenface also alludes to 'terministic' screens thereby widening the potential of what can be included in the discussion because its very nature is focused on the terms through which we negotiate meaning and challenges assumptions we may hold.

\section{Relevance for recent research}

The screenface facilitates rethinking some previous assumptions and conceptions of what it means to teach and to learn. In the following section, I use the screenface to unpack research into other areas to elaborate what kinds of insights this metaphor may provide. This is not to deny the findings already presented, but to allow deeper understanding of these findings and more nuanced questions to be asked and potentially answered. I use examples of blended learning, mobile technologies and virtual environments to demonstrate that how the screenface provides additional insights that may be overlooked.

\section{Blended learning}

In research describing what characteristics aid individuals in effective e-learning, Winter et al. (2010) discuss 'boundary management' - techniques for separating different activities - for students using networked learning. For these students, the screenface has blurred the boundary between learning and social activities. Invoking boundary management, then, is recognising that the screenface can be problematic for students because of 'social' distractions on impeding academic work, but also because academic work may impinge on social spaces (Winter et al. 2010, p. 78). The screenface thus embodies two different scenes in which students are concurrently participating. The effect would be similar to two plays on a single stage. For the students in Winter el al.'s study who reported 'choosing to learn away from computers, disabling email and other alerts and other adjustments to working practices' (p. 78), they effectively managed their screenface, but reduced the number of forms of agency (i.e. disabling email and other alerts) or shifted the scene away from the computer. However, given that these students were engaged in a blended mode of learning, a question arising is 'how well are students blending their use of technologies for learning and social activities?' We seem to talk often about blended learning and, yet the real blending seems to occur for the student at the screenface. Using the pentad to elaborate this, the student (agent) acts (learns/socialises) via the computer/iphone/ipad with both generic and specific applications (agency) at the computer desk/table/other location (scene) for learning/socialising (purpose). So students blend learning with socialising, blend where they learn, and move between scenes to enable particular acts at particular times. Ideally students will finely manage their use of the screenface, although this may be an additional skill needing development prior to engaging in blended modes of learning. Alternatively, we need to frame research into blended learning rather than blended teaching and so encompass how students blend their learning with other forms of interactions at their screenface. 


\section{Mobile devices}

Traxler (2010) discusses how mobile devices open up the "dreams of agency, control, ownership and choice amongst students" while also pointing to some problems. He notes particularly that:

We can say only that the devices owned by students will be, at best, poorly suited to learning. They will all be different, they will be changing - often for reasons that are not technical, not educational and probably not even rational or foreseeable. (Traxler 2010, p. 150)

Focus on devices is perhaps problematic in that we can never assume similarity between devices. For instance, Floridi (2010) notes that we, rather than our devices, are central to the manifestation of the information that we use. The screenface metaphor presented here allows us to move from a device focused problematic toward an information focused problematic. Unpacking the screenface allows us to see 'types' of applications, for instance word processors, browsers, spreadsheets and email clients. These applications are sufficiently similar regardless of device and often overlap (e.g. access to email via a web interface).

Devices may change, but when we consider the screenface, there are potentially powerful commonalities between devices, rather than instances of devices, that should inform our pedagogy. The screenface can be made manifest on many devices, but applications for single devices may become obsolete. The underlying technologies of networking and the screenface are the constants in our battles to keep up. This is not to suggest that students will not need skills to engage with their device, but rather that the commonalities of interacting become the focus of research, teaching and learning.

Contrary to what was demonstrated in the context of Winter et al. (2010) showing students modifying their scene by moving between different applications and processes (see above), Traxler (2010) implies that students physically move between different scenes in order to perform certain tasks. Specifically he states that:

Interacting with a desktop computer takes place in a bubble, in dedicated times and places where the user or student has their back to the rest of world for a substantial and probably premeditated episode. (Traxler 2010, p. 151)

That students interact with their learning "in a bubble" implies that learning is a protected and separate activity that must be engaged in without any distractions. The metaphor of the screenface may in fact burst this bubble because students appear more likely to engage in specific acts in specific locations but also move between acts with different purposes all within a time frame. Consider, for instance, the student who is also a parent, the student who is also working. Each of these 'sandwiches' learning with everyday activities. Thus, the screenface allows us to unpack older metaphors that separate social and learning activities and challenges our assumptions about how students work.

\section{Virtual environments}

Good, Howland, and Thackray (2008) discuss the issues of using Second Life ${ }^{\mathrm{TM}}$ for creating learning environments. They note that traditional teaching scenarios are often replicated in virtual environments, which suggests the need for a newer metaphor for learning. 
Additionally, the use of Second Life "allows the role of the tutor to be 'blurred' in a number of ways" (Good, Howland, and Thackray 2008, p. 169) and that the instructor was "a peer rather than an authority" (p. 170). In the absence of a cohesive metaphor, these role blurrings are seen as something worthy of comment and, yet, the screenface allows us to see that individual agents do indeed have multiple roles which can be switched as necessary, particularly in environments such as Second Life as the role of the instructor shifts towards that of a peer (Good, Howland, and Thackray 2008 , p. 170). This is an area worthy of more than comment and will potentially be a feature of future pedagogy. Co-presence is a feature of many environments and is now playing out in more nuanced ways.

\section{Conclusion}

This introduction to the screenface demonstrates some of the shifts enabled by rethinking the metaphor we use to describe teaching and learning activities. By starting to unpack how we believe students work, and our own assumptions about the teaching/learning nexus, we may find more useful ways of constituting learning and teaching for both our students and ourselves. One of the potential strengths of this metaphor is in reducing fragmentation (Rowland 2006) in teaching and learning by providing a single, yet multiple, elaboration of our core concerns.

The screenface is a useful metaphor, with likely application beyond this initial argument providing new and fruitful questions that can be asked about teaching and learning. It has the potential to allow us to look for the individual in the group (the one in the many) but also to understand how a group of people interact with both the interface and with each other (the many in the many). That is, it allows us to consider the agency of individuals, both teachers and learners, within a learning environment, and to delve deeper into the consequences of our decisions to use particular technologies. While there are limitations to this metaphor, there are similarly limitations to other metaphors for learning and using technology (which includes a chalk or blackboard). Unpacking these assumptions will facilitate a deep appreciation of teaching, learning and interacting within the many different learning environments available to teachers, and potentially, environments yet to be developed.

\section{Acknowledgements}

Bernadette Knewstubb took time to argue with me about the ideas in this paper while simultaneously writing her $\mathrm{PhD}$. I will be forever in her debt for this. Similarly, the reviewers of the initial draft provoked further reflection that has strengthened this paper. I thank them for this and for their willingness to see this paper published.

\section{References}

Arnold, M. (1996) 'The high-tech, post-Fordist school', Interchange, vol. 27, no. 3, pp. 225250.

Arnold, M. (2001) 'The glass screen', Information, Communication \& Society, vol. 5, no. 2, pp. 225-236.

Bramall, S. (2000) 'The educational significance of the interface', Journal of the Philosophy of Education, vol. 34, no. 1, pp. 71-84.

Burke, K. (1945) A Grammar of Motives, Univ of California Press, Berkeley.

Burke, K. (1966) Language as Symbolic Action: Essays on Life, Literature and Method, University of California Press, Berkeley. 
Floridi, L. (2010) Information: a Very Short Introduction, Oxford University Press, Oxford.

Freeman, J. (1974) A Burkean Analysis of the Classroom. 59th American Educational Research Association Annual Meeting. Chicago, IL, April 15-19, 1974.

Good, J., Howland, K. \& Thackray, L. (2008) 'Problem-based learning spanning real and virtual words: a case study in Second Life', ALT-J: Research in Learning Technology, vol. 16 , no. 3 , pp. $163-172$.

Hillman, D., Willis, D. \& Gunawardena, C. (1994) 'Learner-interface interaction in distance education: An extension of contemporary models and strategies for practitioners', American Journal of Distance Education, vol. 8, no. 2, pp. 30-42.

Rodger, S. H. (1995) An interactive lecture approach to teaching computer science, ACM SIGCSE Bulletin, vol. 27, no. 1. pp. 278-282. ACM, New York.

Rowland, S. (2006) The Enquiring University: Compliance and Contestation in Higher Education, Open University Press, Berkshire.

Sharples, M. (2002) 'Disruptive devices: mobile technology for conversational learning', International Journal of Continuing Engineering Education and Lifelong Learning, vol. 12, no. $5 / 6$, pp. $504-520$.

Singh, H. (2003) 'Building effective blended learning programs', Educational Technology, vol. 43 , no. 6 , pp. $51-54$.

Traxler, J. (2010) 'Students and mobile devices', ALT-J: Research in Learning Techno$\log y$, vol. 18, no. 2, pp. 149-160.

Van Dijk, L. A., Van Der Berg, G. C. \& Van Keulen, H. (2001) 'Interactive lectures in engineering education', European Journal of Engineering Education, vol. 26, no. 1, pp. $15-28$.

Winter, J., et al. (2010) Effective e-learning? Multi-tasking, distractions and boundary management by graduate students in an online environment, ALT-J: Research in Learning Technology, vol. 18, no. 1, pp. 71-83.

Wessels, A., et al. (2007) 'Interactive lectures: effective teaching and learning in lectures using wireless networks', Computers in Human Behavior, vol. 23, no. 5, pp. 2524-2537. 